\title{
Relationship between anxiety and static and dynamic balance disorder in subjects with cerebrovascular accident (stroke) diagnosis
}

\author{
Ana Paula Lemos Ferreira*, Danillo Barbosa \\ Universidade Estadual do Centro Oeste do Paraná (PR),Brazil.
}

\section{ABSTRACT}

Background: Sensory systems are responsible for maintaining balance, being vision, vestibular and somatosensory, and all these systems suffer changes in patients with stroke sequelae and studies bet that anxiety is likely to influence the inability of the subject to use these systems, enhancing the postural imbalance in stroke patients. Objective: To analyze the interference of anxiety on the static and dynamic balance of patients diagnosed with stroke. Methods: Fifteen patients with stroke, aged 40 to 80 years, were assessed using the Hospital Anxiety and Depression Scale, Timed Up and Go test for dynamic balance and the Berg Scale for static balance. Data were tabulated in Excel and analyzed using SPSS - Statistical Package for Social Science (version 20.0). Results: Significant values were found for the correlation between anxiety and balance, in which the results analyzed showed that the balance of patients with stroke can be negatively exacerbated due to the anxiety that affects them. Conclusion: It can be concluded from these results that anxiety can alter the balance of these patients and thus, it is shown the importance of a multidisciplinary treatment from the first moment to leverage the treatment.

Keywords: Anxiety; Stroke; Balance.

\section{BACKGROUND}

According to the World Health Organization (WHO), cerebrovascular accident (Stroke) is defined as an acute neurological dysfunction that occurs due to a change in the brain circulation, resulting in signs and symptoms that compromise specific brain sites, persisting for more than 24 hours $^{(1)}$.

With the high rate of stroke patients, it becomes the leading cause of acquired disability worldwide. There is a range of symptoms that stroke causes, in which motor changes become the most evident and feared symptoms by the patient, as they are the causes of several functional limitations, directly interfering with activities of daily living (ADL's) and possibly causing psychological disorders ${ }^{(2)}$.

Anxiety disorder (ED) is one of the psychological disorders that the subject after stroke may have. This disorder is characterized as a state of discouragement, distress and fear, which causes a series of symptoms, such as tachycardia, muscle tension, chronic pain, among others. These emotional and physical changes may be beneficial or harmful to the regularization of the disorders that stroke causes ${ }^{(3)}$.

Burton et al. (2014) report that $20 \%$ to $25 \%$ of patients diagnosed with stroke will have ED at some point in their life and that phobic disorders and generalized anxiety are the most common types of ED following stroke ${ }^{(3,4)}$.

ED are directly linked to reactional psychological factors, in which most of the patients' reports concern themselves that they can no longer control their reactions, no longer speak, have no postural, emotional and cognitive control, among others, and this consequently reflects decreased patient's quality of life, physical changes, as well as inefficient treatment ${ }^{(4)}$.

Postural balance is the ability to hold the body in the desired position and orientation, in which the center of mass is held on its support base ${ }^{(5)}$. The body needs to receive sensory and motor information about its posture in space and the environment in order to maintain balance ${ }^{(6)}$.

Sensory systems are responsible for maintaining balance, being vision, vestibular and somatosensory, and all these systems suffer changes in patients with stroke sequelae and studies bet that anxiety is likely to influence the inability of the subject to use these systems, enhancing the postural imbalance in stroke patients $^{(5)}$. Thus, the aim of the study was to verify whether there is a relationship between anxiety and static and dynamic balance of patients diagnosed with stroke. 


\section{METHODS}

\section{Study Ethics}

The present work obeyed the regulatory norms

by the Unicentro research department, being submitted and approved by the Ethics and Research Committee of the UNICENTRO, in September 06, 2019, with CAAE 17636819.3.0000.0106.

\section{Place and type of study}

This is a quantitative, exploratory, descriptive and randomized research conducted in the Universidade Estadual do Centro Oeste (UNICENTRO), on the premises of the department of physiotherapy course (DEFISIO), in Guarapuava, Paraná.

\section{Sampling}

After signing the consent form, 15 subjects participated in this study, 8 females and 7 males, attended at the Physiotherapy School Clinic (CEFISIO), aged \pm 40 to \pm 80 years, with stroke sequelae.

\section{Inclusion criteria}

Inclusion criteria will be considered subjects attended at the Physiotherapy School Clinic, with diagnosis of stroke, be within the age range proposed in the study, have availability for future assessments and present diagnosis of stroke up to 5 years.

\section{Exclusion criteria}

Subjects who had some type of prosthesis or orthosis in the lower limbs, proprioceptive insoles, significant and uncorrected visual deficit and who could not understand simple orders, such as verbal command to perform the tests, were excluded from the study.

\section{Assessment instruments}

After signing the Informed Consent Form, the subjects underwent a single assessment containing personal data, followed by the Hospital Anxiety and Depression Scale (HADS), Berg Balance Scale (BBS) and the Time Up and Go Test (TUGT). To assess the participants' anxiety level, the HADS was applied, which deals with a scale that was translated and validated by Botega, Bio, Zomignani, Garcia Jr. and Pereira (1995). It has 14 multiple choice items, seven of which are focused on anxiety assessment (HADS-A) and seven on depression (HADS-D) $)^{(7)}$. Each of the items can be scored from zero to three, making a maximum score of 21 points for each scale. The present study will focus on anxietyrelated questions $(1,3,5,7,9,11$ and 13$)$, in which the sum of 0 to 8 points indicates no anxiety and above 9 points indicates anxiety ${ }^{(8)}$. To evaluate the static and dynamic balance, BBS and TUGT were performed. The BBS is a validated instrument adapted for application in Brazil by Miyamoto et al. (2004), is a functional assessment of balance composed of 14 tasks with five items each and a score of 0-4 and a time determined for each task ${ }^{(9)}$, in which 0 - is unable to perform the task and 4 performs the task independently. The total score ranges from 0 to 56 points. The lower the score, the greater the balance deficit (score below 45 points); the higher the score, the better the performance ${ }^{(10)}$.

TUGT assesses seated balance, seat-to-stand transfers, gait stability as well as unsteady gait changes, covers basic activities and is an easy and quick test ${ }^{(10,11)}$. It is a simple test that it begins with the patient sitting on a chair with full back support and is asked to stand up, walk a distance of 3 meters, get around an obstacle and return to the starting point, sitting back on the chair with the total back support ${ }^{(11)}$. This entire course is timed, starting when the patient gets up from the chair and ceased when he returns to sit on the chair, he/she is instructed to perform the task as quickly and safely as possible and the performance is analyzed by counting the amount of time that was required to accomplish the task ${ }^{(12)}$. Subjects who perform the test within 10 seconds indicate independence and no changes in balance; 20 seconds indicates basic dependence and those requiring more than 20 seconds indicate high balance deficit and dependence on many ADLs ${ }^{(12)}$.

\section{Data collection}

For the selection of patients with stroke sequelae, CEFISIO's medical records were read. All selected patients underwent an evaluation of personal data and clarification of doubts about the purpose of the present study. It was also informed that participation was voluntary and that they could leave the study at any time without prejudice and that the results would be kept confidential and would not have any impact on their institutional activities. The subjects who accepted and signed the informed consent form were invited at the first moment of the study to answer the HAD questionnaire, there was no time limit for applying the scale. All participants underwent BBS and TUG practice tests. The TUGT was performed using a Technos Digital Quartz stopwatch $\AA$, to evaluate the walking time from one point to the other. A black chair was also used in which the patients started the test, with $45 \mathrm{~cm}$ height from the seat to the floor, armchair measuring $48 \mathrm{~cm}$ high and $48 \mathrm{~cm}$ wide, with the backrest $52 \mathrm{~cm}$ and also containing armrest. The patient was given a 
command to get up, which it was started counting the stopwatch, walking to the 3-meter mark, turning around and returning to the starting position and the stopwatch was only stopped when he put his back against the chair support. The test was performed three times and considered the shortest time the patient took to perform the test.

For the application of the EEG, a Technos Digital Quartz stopwatch was used to assist in items $2,3,6,7,11,13$ and 14 of the scale; a black chair $43 \mathrm{~cm}$ from the seat to the floor, an armchair measuring $48 \mathrm{~cm}$ high and $48 \mathrm{~cm}$ wide, with the backrest $52 \mathrm{~cm}$ and armrest, and another black chair measuring $47 \mathrm{~cm}$ from the seat to the floor, armchair measuring $40 \mathrm{~cm}$ high and $45 \mathrm{~cm}$ wide, with the backrest $32 \mathrm{~cm}$ and without armrest to assist in items $1,3,4$ and 5 . To assist in item 8 was used a $150 \mathrm{~cm}$ tape measure, a ball of blue color and medium size to perform item 9 and a step of $10 \mathrm{~cm}$ high and $45 \mathrm{~cm}$ wide to assist in item 12. The other items that were not mentioned did not need any object for help, only the understanding and performance of the patient. Both tests were demonstrated before starting and all participants went through a period of adaptation to the tests, prior to data collection, thus minimizing changes due to non-habituation to the environment.

\section{Data analysis}

Data were tabulated in Excel and analyzed using SPSS - Statistical Package for Social Science (version 20.0). All variables were analyzed descriptively using simple frequency (qualitative variables) and measures of position and dispersion (quantitative variables). Data distribution against the normality curve was tested by the Shapiro-Wilk test. To verify the relationship between anxiety and balance scores, stroke time and age, the Pearson correlation test (two-tailed) was used.

\section{RESULTS}

Fifteen patients undergoing care at CEFISIO with stroke were evaluated, 8 females and 7 males, with a mean age of 58.4 years and with a maximum time of 5 years of diagnosis of stroke. Table 1 represents the average results and standard deviation of the scores found in the evaluation.

Table 1. Characterization of the studied sample

\begin{tabular}{ll}
\hline Variables & $\mathrm{n}(\%)$ \\
\hline Gender & $8(53.3)$ \\
Female & $7(46.6)$ \\
Male & $6(40.0)$ \\
Race & $7(46.6)$ \\
White & $2(13.33)$ \\
Brown & \\
Black & $11(73.33)$ \\
Marital Status & $1(6.66)$ \\
Married & $3(20.0)$ \\
Single & $\mathrm{M}(\mathrm{SD})$ \\
Widower/Widow & $11.13 \pm 3.79$ \\
Testes & $14.53 \pm 5.72$ \\
HADS & $41.26 \pm 5.83$ \\
TUG & $58.4 \pm 6.92$ \\
BBS & $3.73 \pm 1.94$ \\
Age & \\
Stroke time & \\
\hline Note: HADS: Hospital Anxiety and Depression Scale; BBS: Berg Balance Scale; TUGT: Time Up and Go test. The data was presented in mean
\end{tabular}

"Note: HADS: Hospital $A n \times$
and standard deviation.

Table 2 shows the relationship between the scores obtained through the HADS scale and the time patients were affected by stroke, age and static and dynamic balance evaluated by TUG and BBS, respectively. Significant values were found for the correlation between anxiety and dynamic and static balance. In Table 2 it can be observed that the value of $r$ showed a moderate negative correlation between HAD and BBS and a strong positive correlation between HAD and TUG. The stroke time and age, however, did not show significant influence on the anxiety levels of the evaluated patients. 
Table 2. Correlations of HADS scores with TUG, BBS, stroke time and age.

HADS

p r

$\begin{array}{ccc}\begin{array}{c}\text { Stroke } \\ \text { time }\end{array} & .782 & .078 \\ \text { BBS } & .007^{*} & -.663 \\ \text { TUGT } & .000^{*} & .832 \\ \text { Age } & .515 & .183\end{array}$

Note: HADS: Hospital Anxiety and Depression Scale; BBS: Berg Balance Scale; TUGT: Time Up and Go test. *There is significance

\section{DISCUSSION}

Anxiety can be triggered in unexpected stress or tension situations where the event is too large to be controlled or ignored ${ }^{(13)}$. Thus, in the present study it was analyzed whether there is a relationship between anxiety and static and dynamic balance in stroke patients. The main results found in this study were the significant correlation of anxiety with the balance of patients with stroke sequelae, which from the results obtained showed that anxiety interferes with the balance of these patients. One reason for this is that anxiety does not receive as much clinical attention compared to visible signs and symptoms.

Rafsten et $\mathrm{al}^{(14)}$, in their systematic review and meta-analysis, 37 studies were found, assessing the prevalence of anxiety after the stroke episode in 13,756 patients using the HADS Scale and found that anxiety was present in $29.3 \%$ of patients during the first year after stroke. It also showed that there is no statistical significance of anxiety prevalence over the years. Schöttke e Giabbiconi ${ }^{(15)}$ in their meta-analysis corroborate this finding, in which they investigated the prevalence of anxiety in patients with life-long stroke sequelae, and reported a prevalence of $20.4 \%$, which they concluded that anxiety may be more age-related than stroke sequelae.

The results of the present study contradict the statements cited above, as it was shown that anxiety is still present until 5 years after the stroke episode in $73.3 \%$ of the patients evaluated, and showed no significant correlation with age. In a study by Rutovic et $\mathrm{al}^{\left({ }^{(16)}\right.}$ with 85 patients, showed a significant number of patients who experienced episodes of post-traumatic stress disorder who had depression $(18.8 \%)$ or anxiety $(10.6 \%)$, compared with those who never had. This study corroborates the results found, since in the sample a value of $73.3 \%$ of patients with anxiety was identified, and this is justified by the signs and symptoms that an unexpected traumatic episode may cause in the subject $^{(2)}$. Postural balance disorders may be caused by several factors that compromise sensory organization ${ }^{(16)}$. It is suspected that postural instability may be related to anxiety, and Gagey and Weber ${ }^{(17)}$ believe this happens in subjects who are in an exacerbated state of anxiety. In the study this hypothesis is confirmed by the TUGT and BBS test applied to patients, which had a significant correlation when compared with anxiety, i.e., anxiety is a factor that directly acts on the balance of patients with stroke sequelae.

Meneghetti et $\mathrm{al}^{(6)}$ evaluated the balance of 22 stroke patients using the BBS, which showed a high risk of falls. In the present study the static balance was also evaluated by the BBS and obtained a moderate negative correlation with anxiety. However, it is important to highlight the main limitations of the study that hindered the results, as the sample number was relatively low and that $33.3 \%$ of the evaluated patients were hobbler, which may induce the results of the TUG test.

\section{CONCLUSION}

It is concluded that subjects treated at the Physiotherapy Clinical School (CEFISIO) with stroke sequelae have anxiety and that it interferes with the static and dynamic balance, a fact of great relevance given the importance of multidisciplinary treatment. It is noteworthy that in the present study an important limitation was the reduced number of patients evaluated and studies published on the subject, so larger studies are suggested to increase representativeness.

Authors' contributions: APLF: Preparation of the research project, submission to the ethics committee, data collection, correction of the project and submission to the journal. DB: Correction of the research project, correction of the article and correction of the journal submission.

Financial support: The authors declare that there was no financial support. 
Conflict of interest: The authors declare that there was no conflict of interests.

\section{REFERENCES}

1. Barcala L, Colella F, Araujo MA, Salgado ASI, Oliveira CS. Balance analysis in hemiparetics patients after training with Wii Fit program. Fisioter. Mov. 2011;24(2):337-43.

2. Chen J, Sun D, Shi Y, Jin W, Wang Y, Xi Q, et al. Alterations of static functional connectivity and dynamic functional connectivity in motor execution regions after stroke. Neuroscience Letters. 2018;686:112-21.

3. Freitas ECG, Ferreira EAG. Alinhamento postural, ansiedade e estresse em adultos jovens. Revista PIBIC. 2007;4(1):81-94.

4. Pedroso VSP, Souza LC, Teixeira AL. Neuropsychiatric syndromes associated with stroke: review of the literature. J. bras. Psiquiatr, vol.63, p. 6-12,2014.

5. Rosa GMMV, Souza WC, Pinto LDP, Garban GA, Serafim AD, Faria ETB. Análise da influência do estresse no equilíbrio postural. Fisioterapia Brasil. 2004;5(1):50-55.

6. Meneghetti $\mathrm{CHZ}$, Delgado GM, Pinto FD, Canonici AP, Regiane M, Gaino C. Equilíbrio em indivíduos com Acidente Vascular Encefálico: Clínica Escola de Fisioterapia da Uniararas. Rev Neurociencias. 2009;17(1):1-5.

7. Bergerot CD, Laros JA, Araujo TCCF. Avaliação de ansiedade e depressão em pacientes oncológicos: comparação psicométrica. PsicoUSF. 2014;19(2):187-97.

8. Marcolino JAMM, Mathias LAST, Filho LP, Guaratini AA, Suzuki FM, Alli LAC. Escala Hospitalar de Ansiedade e Depressão: Estudo da Validade de Critério e da Confiabilidade com Pacientes no Pré-Operatório. Rev Bras Anestesiol. 2007;57(1):52-62.

9. Dias BB, Mota RS, Gênova TC, Tamborelli V, Pereira VV, Puccini PT. Aplicação da Escala de Equilíbrio de Berg para verificação do equilíbrio de idosos em diferentes fases do envelhecimento. RBCEH. 2009;6(2):213-24.

10. Figueiredo KMOB, Lima KC, Guerra RO. Instrumentos de avaliação do equilíbrio corporal em idosos. Revista Brasileira de Cineantropometria \& Desempenho Humano. 2007;9(4):408-413.

11. Dutra MC, Cabral ALL, Carvalho GA. Tradução para o português e validação do teste timed up and go. Revista INTERFACES. 2016;3(9):8188.

12. Santos DG, Pegoraro ASN, Abrantes CV, Jakaitis F, Gusman S, Bifulco SC. Avaliação da mobilidade funcional do paciente com sequela de AVC após tratamento na piscina terapêutica, utilizando o teste Timed Up and Go. Einstein. 2011;9(3):302-6.

13. Souza WC, Rosa GMMV, Gaban G.A, Pinto LDP, Bastista ET, Serafim AD, Silva AMM. A influência da personalidade ansiosa e o estado de ansiedade sobre o equilíbrio postural. Fisioterapia Ser. 2009;4:216-19.

14. Rafsten L, Danielsson A, Sunnerhagen KS. Anxiety after stroke: a systematic review and meta-analysis. J Rehabil Med. 2018;50:769-78.

15. Schottke H, Giabbiconi CM. Post-stroke depression and post-stroke anxiety: prevalenceand predictors. International Psychogeriatrics, 2015;27(11):1805-12.

16. Rutovic S, Kadojic D, Dikanovic M, Solic K, Malojcic B. Prevalence and correlates of post-traumatic stress disorder after ischaemic stroke. Acta Neurologica Belgica. 2019.

17. Gagey PM, Weber B. Uma Breve Historia Posturologia. Posturologia, Regulação e Distúrbios da Posição Ortostática. $2^{\underline{a}}$ ed. São Paulo: Manole, 2000. 